\title{
Detection of Rifampicin Mono-Resistant Mycobacterium Tuberculosis by Genexpert in Patients Attending Tertiary Care Teaching Hospital
}

\author{
Dr. BV Archana ${ }^{1}$, Dr. Ch Navaneetha ${ }^{2 *}$, Dr. G Jyothi Lakshmi ${ }^{3}$
}

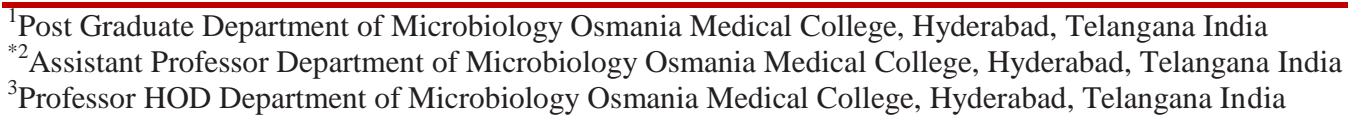

DOI: $10.36347 /$ sjams.2021.v09i01.008

| Received: 20.12.2020 | Accepted: 06.01.2021 | Published: 08.01.2021

*Corresponding author: Dr. Ch Navaneetha

\section{Abstract}

Original Research Article

In India incidence of TB is 27, 90,000, mortality is 4, 23,000 and incidence of MDRTB/RR 1, 47,000. Early detection of TB is the key to successful treatment and reduction of disease transmission. The aim of this study is to determine the Rifampicin resistant, Mycobacterium tuberculosis by Gene Xpert in patient attending TB chest hospital, Hyderabad. All the Samples, Pulmonary and Extra pulmonary, received from clinically suspected cases of Tuberculosis, IP and OP during the study period between March 2018 to October 2018 were processed in the department of Microbiology using Xpert MTB/RIF test version 4.8 (Cepheid) as per the manufacturer's instruction. Result: Prevalence of total MTB culture positive was $34.2 \%(754 / 2202)$ and Rifampicin resistant was $13.7 \%$ (103/754) in the total samples processed. Conclusion: Early detection of TB is the key to successful treatment and reduction of disease transmission. Gene Xpert was found to be useful assay for rapid detection of MTB within 2 hours with additional advantage of identifying Rifampicin resistance with high sensitivity and specificity.

Key words: Mycobacterium tuberculosis complex, Prevalence, Rifampicin resistance, multidrug resistance TB, CBNAAT, rpo B gene.

Copyright (C) 2021 The Author(s): This is an open-access article distributed under the terms of the Creative Commons Attribution 4.0 International License (CC BY-NC 4.0) which permits unrestricted use, distribution, and reproduction in any medium for non-commercial use provided the original author and source are credited.

\section{INTRODUCTION}

Tuberculosis continues to be a major public health problem in India as well as worldwide. As of global TB 2017 report, incidence of TB in India is nearly 28, 00,000 (28 lakhs) which accounts for one fourth of global TB burden. Mortality due to TB is 4, 23,000. Incidence of MDR/ RR TB is $1,47,000$. The rate of MDR TB as per the First National Drug Resistance survey results is $2.84 \%$ among new TB patients and in previously treated is $11.6 \%$ [1].

Drug resistant Tuberculosis is a major public health problem that threatens progress made in TB cases and its control worldwide. As per, global tuberculosis 2017 worldwide report, there were 5, 58,000 new cases (range 4, 83,000- 6, 39,000) of Rifampicin resistant TB. Among Rifampicin resistant TB cases, $3.5 \%$ new and $18 \%$ of previously treated tuberculosis cases and $82 \%$ had multidrug resistant TB (MDR TB) [2].

Genetic mutations in tubercle bacilli that develop due to an inadequate or poorly administered treatment regimens, weak services program that led to delay detection and initiation of effective treatment of drug-resistant TB and non-adherence to treatment lead to development and spread of Drug resistant Tuberculosis [3]. Differentiation of NTM from mycobacterium tuberculosis is difficult with microscopy. Due to paucibacillary state, extrapulmonary specimen's microscopy results are often negative. Culture which is the gold standard for TB diagnosis often leads to considerable delays, compromising patient care [4].

CBNAAT is a mycobacterium tuberculosis complex specific, cartridge base nucleic acid amplification assay, having fully integrated and automated amplification and detection using real time PCR, providing results within 100 minutes. It is highly specific test which uses 3 specific primers and 5 unique molecular probes to target the rpo B gene of Mycobacterium tuberculosis. No cross reactions were observed with many other bacterial species, including a comprehensive panel of Mycobacteria, therefore excluding NTM. Critical validation trails done in 4 distinctly diverse settings showed, a single CBNAAT test detects $92.2 \%$ of culture positive patients, with a specificity of $99 \%$ (as compared to $59.9 \%$ sensitivity of a single direct sputum smear)[5]. 
BV Archana et al; Sch J App Med Sci, Jan, 2021; 9(1): $42-46$

The Xpert assay is highly rapid, sensitive and specific in diagnosis of both pulmonary and extra pulmonary tuberculosis [6-8]. Early detection of TB is the key to successful treatment and reduction of disease transmission. As little data is available on prevalence of TB and MDRTB/RR in south India the present study was done with an aim to determine the Prevalence of Rifampicin mono-resistant Mycobacterium tuberculosis among TB patients attending TB Chest, a tertiary care teaching Hospital.

\section{Materials ANd Methods}

A prospective study was conducted from March 2018 to October 2018 at tertiary care teaching Hospital. The study was ethically approved by the institute and ethical committee.

Patients having clinical, radiological features suggestive of $\mathrm{TB}$, old cases of $\mathrm{TB}$ with recurrence, failure of ATT after 1 month, defaulters, all age groups, both sexes, PLHIV(people living with HIV) were included in the study. Patients who provided inadequate specimen that is heavily bloodstained or contaminated with PCR inhibitors like formalin, xanthochromic CSF samples were excluded.

A total of 2369 samples were collected. Sputum- 1494, Broncho alveolar lavage (BAL) -
246, Gastric aspirate- 5, Pleural fluid-268, Biopsy30,Pus-130, synovial fluid- 6, CSF-10, Ascitic fluid-2.

From each presumptive pulmonary TB patient 2-4 $\mathrm{ml}$ of sputum was collected. In case of presumptive extrapulmonary TB 2-4 $\mathrm{ml}$ of pus, lymph node aspirates, CSF, pleural fluid or peritoneal fluid samples were collected. Samples were collected in a sterile, dry wide necked and leak proof container and were labeled with unique sample number, date, time of collection. Samples were immediately processed for gene Xpert MTB Rifampicin assay. The samples were inspected for quality and appropriate samples reagent was added to the sample in ratio 2:1 and lid was closed. Sample was then shaken for 10 to 20 minutes and incubated for approximately 10 minutes. Sample was shaken again and further incubated for 5 minutes. The liquid samples were then transferred into the gene Xpert cartridge in the gene Xpert MTB/Rifampicin assay system. The computerized system was then operated according to the standard operating procedure to carry out analysis. Results were automatically generated after 2 hours, indicating if MTB was detected or not detected, where MTB was detected, the gene Xpert automatically generated result indicating if the MTB is Rifampicin resistant or not resistant [9].

\section{Results}

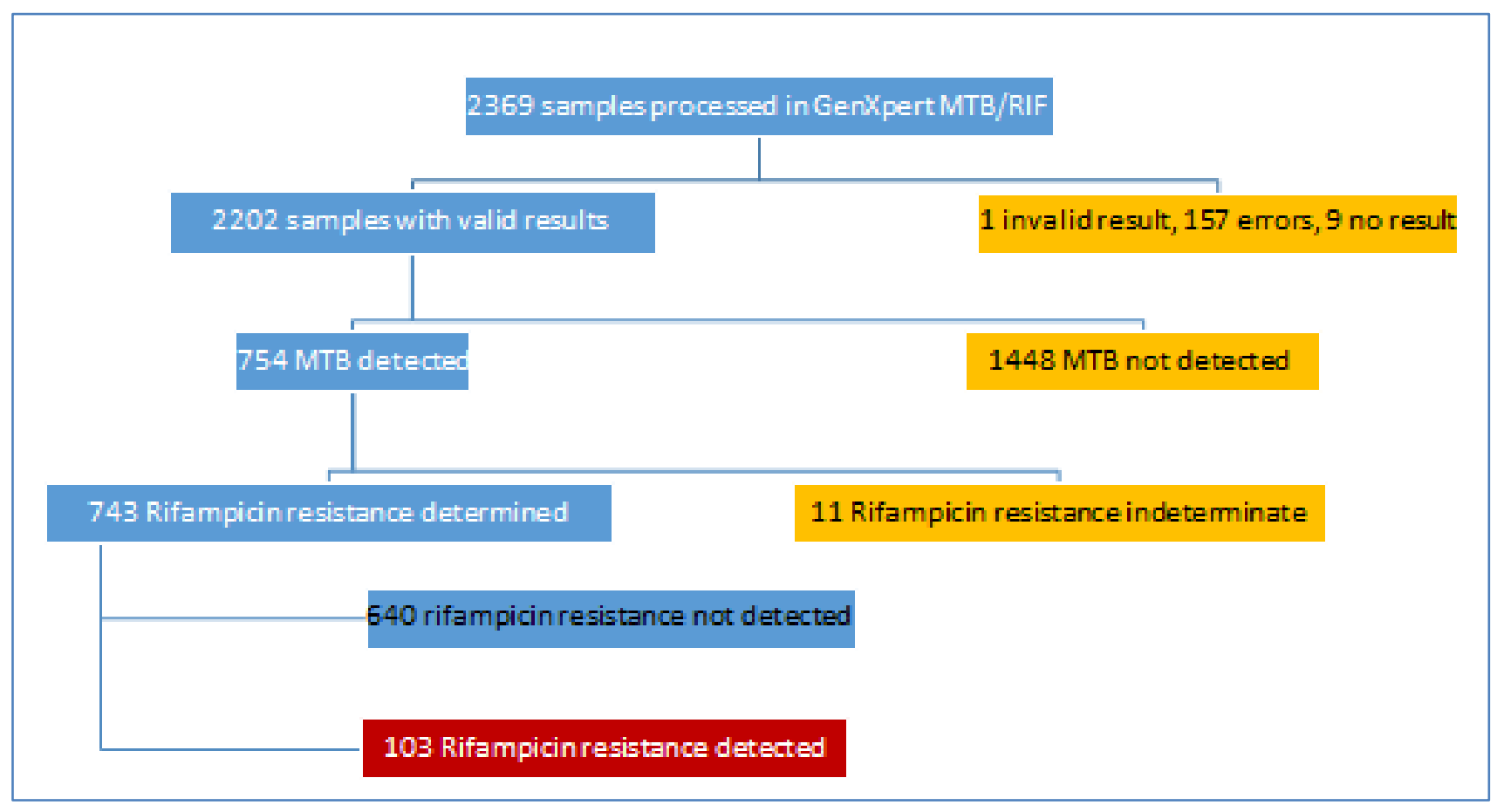

Fig-1: Overall distribution of samples results

Out of the total 2369 different types of samples collected and processed, 2202 samples showed valid results. Remaining 167 showed errors. Among 2202 samples which showed valid results, $754(34.2 \%)$ were
MTBC positive.11 cases showed indeterminate results to Rifampicin resistance, 640 were Sensitive to Rifampicin and 103(13.7\%) were Rifampicin resistance cases. 
BV Archana et al; Sch J App Med Sci, Jan, 2021; 9(1): 42-46

Table-1: Prevalence of Rifampicin resistance among different types MTBC positive specimens

\begin{tabular}{|l|l|l|l|}
\hline Sample & Total & Positive & R/R \\
\hline Biopsy & 30 & $30.0 \%(9 / 30)$ & $44.4 \%(4 / 9)$ \\
\hline BAL & 247 & $21.5 \%(53 / 247)$ & $20.7 \%(11 / 53)$ \\
\hline Sputum & 1500 & $37.9 \%(569 / 1500)$ & $13.5 \%(77 / 569)$ \\
\hline PF & 270 & $11.9 \%(32 / 270)$ & $12.5 \%(4 / 32)$ \\
\hline Pus & 131 & $66.4 \%(87 / 131)$ & $8.0 \%(7 / 87)$ \\
\hline Synovial fluid & 7 & $42.9 \%(3 / 7)$ & 0 \\
\hline CSF & 10 & $10 \%(1 / 10)$ & 0 \\
\hline GA & 5 & 0 & 0 \\
\hline Ascitic fluid & 2 & 0 & 0 \\
\hline Total & 2202 & $754(34.2 \%)$ & $103(13.7 \%)$ \\
\hline
\end{tabular}

Overall prevalence of MTBC is $34.2 \% .13 .7 \%$ Rifampicin resistance among TB cases with maximum prevalence seen in Biopsy specimens followed by BAL samples.

Table-2: Prevalence of Rifampicin resistance among MTB Culture Positive different age groups

\begin{tabular}{|l|l|l|l|}
\hline Age group in years & Total & Positive & R/R \\
\hline $0-20$ & 356 & $128(35.9 \%)$ & $22(17.2 \%)$ \\
\hline $21-40$ & 1013 & $371(36.6 \%)$ & $52(14.0 \%)$ \\
\hline $41-60$ & 650 & $209(32.2 \%)$ & $24(11.5 \%)$ \\
\hline Above 60 & 183 & $46(25.1 \%)$ & $5(10.8 \%)$ \\
\hline
\end{tabular}

Highest prevalent age group was 0 to 20 years $17.2 \%$ (22/128/356) followed by $41-60$ years and above 60 years cases.

Table-3: Prevalence of Rifampicin resistance among MTB Positive Males and Females

\begin{tabular}{|l|l|l|l|}
\hline Gender & Total cases & MTBC positive & Rifampicin resistant \\
\hline Males & 1300 & 478 & $63(13.2 \%)$ \\
\hline Females & 902 & 276 & $40(14.5 \%)$ \\
\hline
\end{tabular}

Prevalence of Rifampicin resistance is more in females $14.5 \%(40 / 276 / 902)$ than in males $13.3 \%(63 / 478 / 1300)$ MTBC positive cases.

Table-4: Prevalence of Rifampicin resistance in Pulmonary \& Extra pulmonary TB patients

\begin{tabular}{|l|l|l|l|}
\hline Sample type & Total & MTB Positive & R/R \\
\hline Pulmonary & 1752 & $622(35.5 \%)$ & $88(14.1 \%)$ \\
\hline Extra Pulmonary & 450 & $132(29.3 \%)$ & $15(11.4 \%)$ \\
\hline
\end{tabular}

Among MTBC positive pulmonary and extra pulmonary cases, $14.1 \%(88 / 622 / 1752)$ and $11.4 \%$ $(15 / 132 / 450)$ is the prevalence of Rifampicin resistance respectively. Prevalence of Rifampicin resistance is more in pulmonary cases than in extrapulmonary cases.

Table-5: Prevalence of Rifampicin resistance in PLWHIV with TB coinfection and in Non-HIV group with only TB

\begin{tabular}{|l|l|l|l|}
\hline Cases & Total & MTB Positive & R/R \\
\hline PLHIV with TB & 451 & $42(9.3 \%)$ & $2(4.8 \%)$ \\
\hline Only TB & 1751 & $712(40.7 \%)$ & $101(14.2 \%)$ \\
\hline
\end{tabular}

PLHIV with TB and Non-HIV group with TB is $4.8 \%(2 / 42 / 451)$ and $14.2 \% \quad(101 / 712 / 1751)$ respectively. Prevalence of Rifampicin resistance is more in Non-HIV group with MTBC than in PLHIV and MTBC co-infection.

\section{DiscuSSION}

In the present study prevalence of MTB infection was $34.2 \%$. The studies done by Praveen B. Gautam et al. (32.9\%), from West Uttar Pradesh,
2018[10], Alvarez-uria et al., at Uttar Pradesh,2012[19] and Dinic et al. (31.4\%) at Nigeria, 2012 [11] were similar to present study MTB infection prevalence.

In the present study, prevalence of Rifampicin resistant in MTB positive cases was found to be $13.7 \%$. Which correlated with the studies done by Mi Zhou et al. (17.2\%), at Sichuan, China, 2018 [12], Reddy et al. (9.9\%), at Ananthapur district, AP, 2017[13) and Kaur et al. (9.2\%) [20] at Malwa region from Punjab, 2016. 
BV Archana et al; Sch J App Med Sci, Jan, 2021; 9(1): $42-46$

Though Mumbai reports a very high incidence of Rifampicin resistance of $66.8 \%$ as seen in Chowgule et al. study, 1998 [14].

In our study, prevalence of Rifampicin resistance MTB cases high predominance was seen in the age group 0 to 20 years $(17.2 \%$ )which was similar to the study done by Villegas et al. (below 44 years)[16] at North district of Lima, 2016. In the present study, Rifampicin resistant MTB cases was higher in females $14.5 \%$ when compared to males $13.2 \%$ similar to studies done by Masenga et al. at Livingston, Zambia, 2015[15] and Villegas et al. at North district of Lima, 2016[16]. The likely reasons for predominance of females over males might be due to, majority of females are illiterate and are home makers who does not even have easy access to healthcare facilities, poor nutritional status which might be due to social and health seeking behaviour difference.

In the present study, the prevalence of Rifampicin resistant MTB cases was higher in pulmonary $(14.1 \%)$ cases when compared to extra pulmonary (11.4\%) TB cases. The study done by the Chakra borty et al. found $13.7 \%$ from pulmonary and $8.6 \%$ from extra-pulmonary cases[17], and study done by the Praveen B. Gautam et al. found $27.6 \%$ from pulmonary and $21 \%$ from extra-pulmonary cases [10] which were supportive to present study findings. Predominance of rifampicin resistance among pulmonary cases over extra-pulmonary cases can be explained by the spread of infection through aerosols inhalation, which has high chances of spreading the infection in the community. In case of extra-pulmonary cases, spread of infection through hematogenous route from primary focus like lungs of the patient or direct inoculation of Mycobacterium at the site of infection as a result of trauma, injury and surgery can occur.

In the present study only 2 patients out of 103 Rifampicin resistant MTB were HIV seropositive. This is in accordance to the study done by Gautam et al. at West Utter Pradesh, 2018[10]which showed only 1patient out of 144 RRTB cases as HIV seropositive and study done by Gaude et al. at Northern Karnataka, 2015[18], which showed only 2 patients out of 36 RRTB cases. Low prevalence of rifampicin resistance in PLHIV coinfection of TB than only TB cases might be because of population level improvement in HIV and TB control care.

\section{CONCLUSION}

Molecular technique has revolutionized the diagnosis of TB (both PTB and EPTB) as well as MDR $\mathrm{TB}$ and TB in PLHIV. CBNAAT (Xpert MTB / Rifampicin) can be used in field condition, sub district level, where 24 hours electricity is available as it requires minimum training and biosafety. Rifampicin resistance is considered as surrogate marker of MDR TB as practically all rifampicin resistant bacilli are resistant to INH. However, it should be remembered that a positive result suggests but a negative result do not exclude TB as well as MDR TB. At present CBNAAT has not totally replaced the traditional smear and culture for TB.WHO recommends CBNAAT for diagnosis of TB and detection of rifampicin resistance in presumptive vulnerable paediatric age group, smear negative with $\mathrm{X}$-ray suggestive of TB, and all diagnosed TB patients non-responders to treatment, DRTB contacts, previously treated TB, TB HIV co infection and newly diagnosed TB. Early detection of TB is the key to successful treatment and reduction of disease transmission

\section{REFERENCES}

1. Central TB Division, Directorate General of Health Services, Ministry of health and family welfare nirman bhawan, New Delhi. Available at: http://www.tbcindia.gov.in. Revised National TB Control Programme, annual status report 2018.

2. Tuberculosis WHO Global Tuberculosis Report 2018. Available at: http/www.whoint/tb/ publication/factsheet_global.pdf.

3. Guidelines on programmatic management of drug resistant tuberculosis in India, RNTCP 2017.

4. Bankar S, Set R, Sharma D, Shah D, Shastri J. Diagnostic accuracy of Xpert MTB/RIF assay in extrapulmonary tuberculosis. Indian $\mathbf{J}$ Med Microbiol. 2018; 36:357-63.

5. R Dewan, S Anuradha, A Khanna, S Garg, S Singla, P Ish, S Agarwal, A Narayana H, M Hanif, H Singh, S Uppal. Role of cartridge-based nucleic acid amplification test (CBNAAT) for early diagnosis of pulmonary tuberculosis in HIV. Journal, Indian Academy of Clinical Medicine 2015; 16(2): 114-7.

6. Tessema B, Beer J, Emmrich F, Sack U, Rodloff AC. First- and second-line anti-tuberculosis drug resistance in Northwest Ethiopia. Int J Tuberc Lung Dis. 2012;16(6):805-11.

7. Getahun M, Ameni G, Kebede A, Yaregal Z, Hailu E, Medihn G, Demssie D, Girmachew F, Fiseha Y, Meaza A, Dirse N. Molecular typing and drug sensitivity testing of Mycobacterium tuberculosis isolated by a community-based survey in Ethiopia. BMC public health. 2015 Dec;15(1):1-7.

8. Story BE, Helb D. Evaluation of the analytical performance of the Xpert MTB/RIF assay. J Clin Microbiol. 2010;48(7):2495-501.

9. World health Organization. Standard Operating Procedure [SOP]: Specimen Processing of CSF, Lymph Nodes and Other Tissues for Xpert MTB/RIF. World health Organization; 2014.

10. Gautam PB, Mishra A, Kumar S. Prevalence of rifampicin resistant mycobacterium tuberculosis and associated factors among presumptive tuberculosis patients in eastern Uttar Pradesh: a cross sectional study. Int J Community Med Public Health. 2018; 5:2271-6. 
BV Archana et al; Sch J App Med Sci, Jan, 2021; 9(1): $42-46$

11. Dinic L, Akande P, Idigbe EO, Ani A, Onwujekwe D, Agbaji O, Akanbi M, Nwosu R. Genetic determinants of drug-resistant tuberculosis among HIV infected patients in Nigeria. J Clin Microbiol. 2012;50(9):2905-9.

12. Zhou M, Liu S, Li Q, Wang Q, Zhu M, Cao L, Wang D, Xu Y, Zheng T, Ye Q, Hu X. Drug resistance characteristics of Mycobacterium tuberculosis isolates between 2014 and 2017 in Sichuan, China: A retrospective study. PloS one. 2018 Dec 31;13(12):e0209902.

13. Reddy R, Alvarez-Uria G. Molecular epidemiology of rifampicin resistance in mycobacterium tuberculosis using the GeneXpert MTB/RIF assay from a rural setting in India. Journal of pathogens. 2017 Oct 26;2017.

14. Chowgule RV, Deodhar L. Pattern of secondary acquired drug resistance to antituberculosis drug in Mumbai, India -1991-1995. Indian J Chest Dis Allied Sci. 1998; 40:23-31.

15. Masenga SK, Mubila H, Hamooya BM. Rifampicin resistance in mycobacterium tuberculosis patients using GeneXpert at Livingstone Central Hospital for the year 2015: a cross sectional explorative study. BMC infectious diseases. 2017 Dec;17(1):14.

16. Villegas L, Otero L, Sterling TR, Huaman MA, Van der Stuyft P, Gotuzzo E, Seas C. Prevalence, risk factors, and treatment outcomes of isoniazid- and rifampicin-mono-resistant pulmonary tuberculosis in Lima, Peru. PloS one. 2016 Apr 5;11(4):e0152933.

17. Chakraborty S, Chakraborty A, Talukder T, Mukherjee M, Chatterjee T. Prevalence of Mycobacterium tuberculosis Strains Isolated from Both Pulmonary and Extra Pulmonary Samples and Their Resistance to Rifampicin: A Study from Kolkata and Surrounding Suburbs. J Tuberculosis Res. 2016; 4:61-71.

18. Gaude GS, Kumar P, Hattiholli J. Drug resistance patterns among pulmonary tuberculosis patients in tertiary care hospital in northern Karnataka. J Med Trop. 2015; 17:81-6.

19. Alvarez-Uria G, Azcona JM, Midde M, Naik PK, Reddy S, Reddy R. Rapid diagnosis of pulmonary and extra-pulmonary tuberculosis in HIV-infected patients. Comparison of LED Fluorescent Microscopy and the GeneXpert MTB/RIF assay in a district hospital in India. Tuberc Res Trea. 2012; 2012:1-4.

20. Ramandeep Kaur, Neerja Jindal, Shilpa Arora, and Shajla Kataria. Epidemiology of Rifampicin Resistant Tuberculosis and Common Mutations in rpoB Gene of Mycobacterium tuberculosis: A Retrospective Study from Six Districts of Punjab (India) Using Xpert MTB/RIF Assay. J Lab Physicians. 2016 Jul-Dec; 8(2): 96100. 